\title{
Optimization of L-methionine Bioconversion to Aroma-active Methionol by Kluyveromyces lactis Using the Taguchi Method
}

\author{
Matthew K. P. Koh ${ }^{1}$, Jingcan $\operatorname{Sun}^{1}$ \& Shao-Quan Liu ${ }^{1,2}$ \\ 1 Food Science and Technology Programme, Department of Chemistry, National University of Singapore, \\ Singapore \\ ${ }^{2}$ National University of Singapore (Suzhou) Research Institute, No. 377 Linquan Street, Suzhou Industrial Park, \\ Suzhou, Jiangsu, China \\ Correspondence: Shao-Quan Liu, Food Science and Technology Programme, Department of Chemistry, \\ National University of Singapore, Science Drive 3, Singapore. Tel: 65-6516-2687; Fax: 65-6775-7895. E-mail: \\ chmlsq@nus.edu.sg
}

Received: June 23, 2013 Accepted: July 20, 2013 Online Published: July 23, 2013

doi:10.5539/jfr.v2n4p90 URL: http://dx.doi.org/10.5539/jfr.v2n4p90

\begin{abstract}
The bioproduction of methionol through fermentation was performed by Kluyveromyces lactis KL71 in coconut cream supplemented with L-methionine (Met). This bioprocess was successfully optimized with the Taguchi method applying the $\mathrm{L}_{27}\left(3^{13}\right)$ orthogonal array. Among these studied factors, shaking speed was found to be the most significant factor that affected the bioproduction of methionol, followed by incubation time, $\mathrm{pH}$ level and Met concentration. The optimum fermentation conditions were determined as follows: $0.45 \%(\mathrm{w} / \mathrm{v}) \mathrm{of} \mathrm{Met,} 48 \mathrm{~h}$ of incubation, shaking speed of $160 \mathrm{rpm}, 0.05 \%(\mathrm{w} / \mathrm{v})$ of yeast extract (YE), $0 \mathrm{mg} / \mathrm{L}$ of diammonium phosphate (DAP) and $\mathrm{pH}$ of 6.3. Under the optimum conditions, the signal to noise $(\mathrm{S} / \mathrm{N})$ ratio achieved was 59.9 decibels $(\mathrm{dB})$, which was in good agreement with the predicted $\mathrm{S} / \mathrm{N}$ ratio of $58.2 \mathrm{~dB}$. The average yield of methionol obtained under the optimum fermentation conditions was $990.1 \pm 49.7 \mu \mathrm{g} / \mathrm{mL}$. This indicates that the Taguchi method was effective for the optimization of bioproduction of methionol by K. lactis.
\end{abstract}

Keywords: methionol, L-methionine, bioproduction, Kluyveromyces lactis, Taguchi method

\section{Introduction}

Volatile sulphur flavour compounds (VSFCs) are important sulphur-containing aroma compounds that play a considerable role in the flavour of many food products (Ugliano \& Henschke, 2009; Yvon \& Rijnen, 2001). Some of the VSFCs commonly found in food products are methanethiol (MTL), dimethyl disulphide (DMDS), dimethyl trisulfide (DMTS), 3-methylthio-1-propanal (methional) and 3-methylthio-1-propanol (methionol). The flavour compound of interest in this study was methionol, which has a distinct cauliflower- and cabbage-like aroma when present at levels exceeding its threshold level of 1 ppm in wine (Mestres, Busto, \& Guasch, 2000). Although the presence of methionol may be detrimental to the quality of wines, this compound is in fact of great importance in the overall aroma of soy sauce and cheese (Ugliano et al., 2009; Yvon et al., 2001).

The production of flavour compounds via chemical synthesis is commonly practiced but its major disadvantage is the production of undesirable racemic mixtures (Vandamme \& Soetaert, 2002). In addition, health-conscious consumers may have an aversion to the use of chemically synthesized flavourings in food products. Hence, the flavour industry has realized the importance of moving towards developing flavours through bioprocesses such as fermentation, where microorganisms are exploited for the bioconversion of precursors such as amino acids to form desirable flavour compounds. Methionol can be produced by the bioconversion of sulphur-containing amino acids like L-methionine (Met) via Ehrlich pathway which is shown in Figure 1 (Landaud, Helinck, \& Bonnarme, 2008).

The Ehrlich pathway is an enzymatic pathway that results in the formation of methionol. This pathway starts with Met undergoing a transamination process to form $\alpha$-keto- $\gamma$-(methylthio) butyric acid ( $\alpha$-KMBA), followed by a decarboxylation process to form methional, which is then subsequently reduced to form methionol (Landaud et al., 2008; Lopez del Castillo-Lozano, Delile, Spinnler, Bonnarme, \& Landaud, 2007). Besides methionol, minor VSFCs such as MTL, DMDS, DMTS, dimethyl tetrasulphide (DMQS), 
3-methylthio-1-propionic acid (3-MTP acid) and 3-methylthio-1-propionic acetate (3-MTPA) may also be produced (Figure 1).

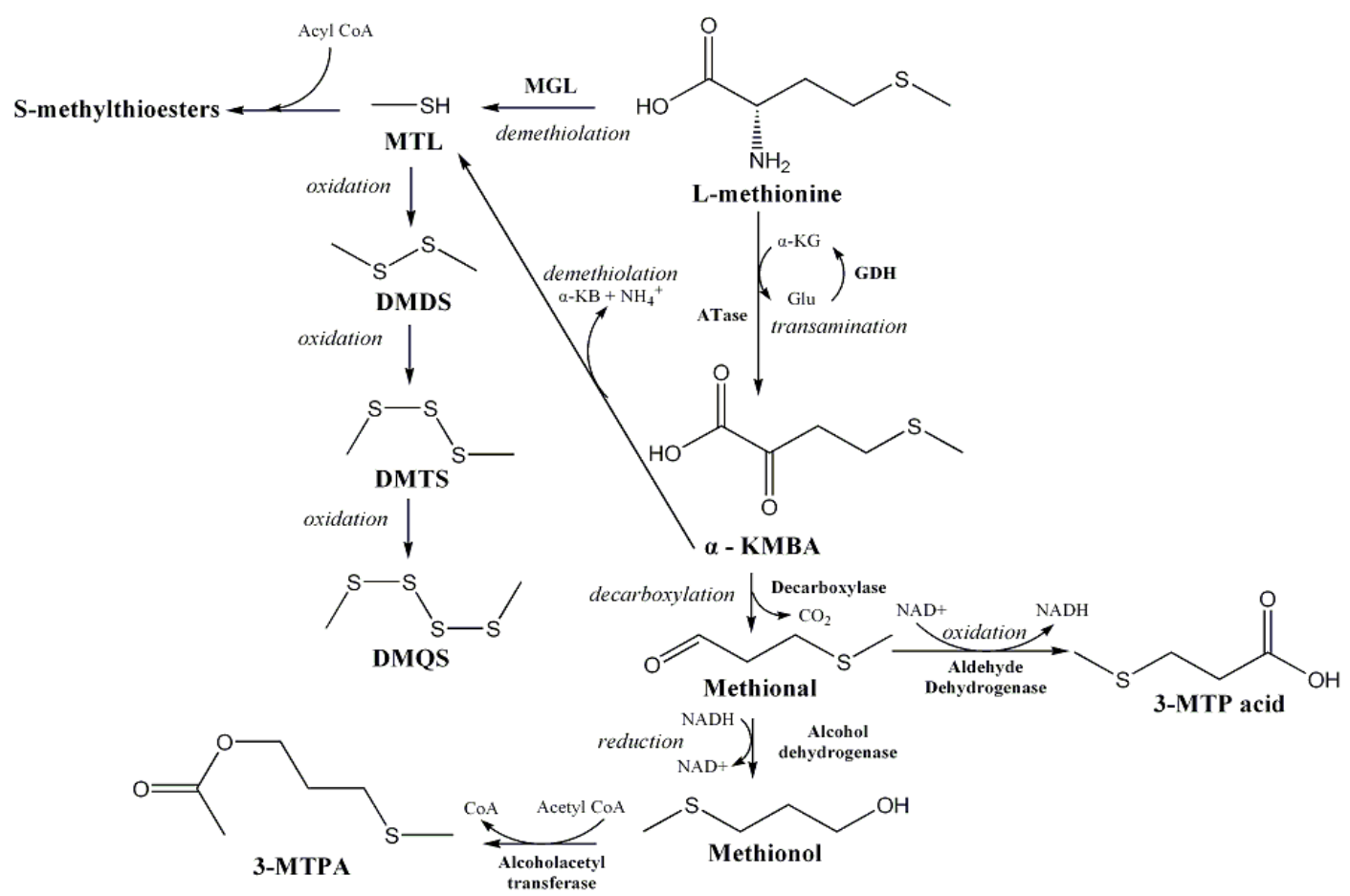

Figure 1. Metabolic pathways of Met catabolism to produce VSFCs. ATase, aminotransferase; $\alpha-\mathrm{KB}$, alpha-ketobutyrate; $\alpha$-KG, alpha-ketoglutarate; Glu, glutamate; GDH, glutamate dehydrogenase; $\alpha$-KMBA, $\alpha$-keto- $\gamma$-(methylthio) butyrate; MGL, methionine $\gamma$-lyase; MTL, methanethiol; DMDS, dimethyl disulphide; DMTS, dimethyl trisulphide; DMQS, dimethyl tetrasulphide; 3-MTP acid, 3-methylthio-1-propionic acid; 3-MTPA, 3-methylthio-1-propyl acetate (Etschmann, Kötter, Hauf, Bluemke, Entian, \& Schrader, 2008; Landaud, et al., 2008; Lopez del Castillo-Lozano et al., 2007)

In this study, Kluyveroymces lactis (K. lactis) was employed for the production of methionol because it is well known to contribute to the production of VSFCs in the cheese-ripening process (Landaud et al., 2008). The bioproduction of methionol from $K$. lactis yeast was previously optimized using the classical method of varying one variable at a time while keeping the others at a predetermined level (Seow, Ong, \& Liu, 2010). However, this traditional method is inefficient at times as it requires numerous experiments that are both labour- and time-intensive. Therefore, multivariate techniques such as response surface methodology (RSM) and the Taguchi method are commonly utilized as tools for optimization processes. The working principle of RSM requires the pre-screening of variables to identify those that have significant effects on the outcome (Bezerra, Santelli, Oliveira, Villar, \& Escaleira, 2008). Although RSM utilizes a multi-factorial experimental design for optimization, it is a challenge to study many variables at one time by RSM as this methodology would require a large number of experiments.

The application of fractional factorial design methods such as the Taguchi method allows a more flexible way of studying several parameters using a small number of experimental trials (Ross, 1996). This is achieved by the design of an orthogonal array (OA) that is reported to be both efficient and cost-effective (Peace, 1993). Although the Taguchi method has been widely applied in the manufacturing industry, this method has only been explored, to a limited extent, as a way of optimizing processes in fermentation and food processing (Prakasham, Rao, Rao, \& Sarma, 2005; Rao, Prakasham, Prasad, Rajesham, Sarma, \& Rao, 2004). A recent review also highlighted the application of the Taguchi method in biotechnology where the method was shown to be successful in increasing the efficiency of several biotechnological processes (Rao, Kumar, Prakasham, \& Hobbs, 2008).

Due to the aforementioned advantages of the Taguchi method, this method was exploited in the present work to optimize methionol bioproduction by K. lactis. Although the Taguchi method using orthogonal array (OA) to 
design experiment allows the study of interactive effects between factors, the working power of an OA design is limited compared to a full factorial design. Nevertheless, leveraging off the attractive potential of the Taguchi method in fermentation processes, it was interesting to explore the application of this method in the current study. The objective of the present study was to optimize the fermentation conditions using the Taguchi method to produce substantial amounts of methionol via L-methionine catabolism by $K$. lactis yeast in coconut cream using an OA layout of $\mathrm{L}_{27}\left(3^{13}\right)$. Coconut cream was chosen as the fermentation medium as it contains sufficient nutrients for yeast growth and is high in fat which retains volatile flavour compounds.

\section{Method}

\subsection{Media and Preculture Preparation}

The nutrient broth consisted of $0.25 \%(\mathrm{w} / \mathrm{v})$ of Bacto $^{\mathrm{TM}}$ yeast extract (YE) (BD, Franklin Lakes, NJ, USA), $0.25 \%(\mathrm{w} / \mathrm{v})$ of malt extract (Oxoid, Basingstoke, UK), $0.25 \%(\mathrm{w} / \mathrm{v})$ of peptone (Oxoid, Basingstoke, UK) and $2.0 \%(\mathrm{w} / \mathrm{v})$ of glucose (Glucolin ${ }^{\circledR}$, Glaxo Wellcome Celon Limited, Moratuwa, Sri Lanka) was used to prepare the pure culture. The $\mathrm{pH}$ level of the nutrient broth was adjusted to 5.0 using $1.0 \mathrm{M}$ hydrochloric acid $(\mathrm{HCl})$. Two loopfuls of freeze-dried K. lactis KL71 yeast (Danisco, Singapore) were added into the $15 \mathrm{~mL}$ portion of sterilized nutrient broth $\left(121{ }^{\circ} \mathrm{C}\right.$ for $\left.15 \mathrm{~min}\right)$ and incubated at $30{ }^{\circ} \mathrm{C}$ for $24 \mathrm{~h}$. The pure culture was then dispensed in $1.5 \mathrm{~mL}$ aliquots into sterilized culture vials that were kept at $-80{ }^{\circ} \mathrm{C}$ before use.

The frozen pure yeast culture was thawed and $1.0 \mathrm{~mL}$ of it was added into $100-\mathrm{mL}$ bottles containing $20 \mathrm{~mL}$ of UHT-processed and aseptically packed coconut cream which functioned as the experimental preculture medium ( $25.4 \%$ fat, $4.6 \%$ protein, $1.3 \%$ carbohydrate, Kara, Fairteck Holding Pte. Ltd., Singapore). After incubation for $24 \mathrm{~h}$ at $30^{\circ} \mathrm{C}$, spread plating on potato dextrose agar (PDA) plates was conducted to determine cell counts in the culture. The preculture with a cell count of about $10^{7} \mathrm{CFU} / \mathrm{mL}$ was obtained and used for the fermentations.

\subsection{Fermentation Conditions and Experimental Design}

Table 1. Parameters and their levels employed in the Taguchi method for optimizing the bioproduction of methionol

\begin{tabular}{|c|c|c|c|}
\hline \multirow{2}{*}{ Parameters } & \multicolumn{3}{|c|}{ Levels } \\
\hline & 1 & 2 & 3 \\
\hline A: $\quad$ Met $(\% \mathrm{w} / \mathrm{v})$ & 0.15 & 0.30 & 0.45 \\
\hline B: Incubation time (h) & 24 & 48 & 72 \\
\hline C: Shaking speed (rpm) & 0 & 80 & 160 \\
\hline D: $\quad$ YE $(\%$ w/v $)$ & 0 & 0.05 & 0.20 \\
\hline E: $\quad$ DAP (mg/L) & 0 & 250 & 500 \\
\hline F: $\mathbf{p H}$ & 4.0 & 5.0 & 6.3 \\
\hline
\end{tabular}

Fermentation was carried out by inoculating $1 \%(\mathrm{v} / \mathrm{v})$ of preculture into the experimental culture media which was $40 \mathrm{~mL}$ of coconut cream. The experimental culture media was supplemented with different concentrations of Met ( $\geq 99 \%$, non-animal source, Sigma, Unterhaching, Germany), YE and diammonium phosphate (DAP) ( $\geq$ $98 \%$, Sigma, Japan) and was subjected to different treatments according to the experimental design. A total of six parameters were studied including Met concentration (\%w/v), incubation time (h), shaking speed (rpm), YE concentration $(\% \mathrm{w} / \mathrm{v})$, nitrogen level by addition of DAP $(\mathrm{mg} / \mathrm{L})$ and $\mathrm{pH}$ level. In addition to the main effects of the parameters studied, two interactive effects between parameters were also investigated: Met level and incubation time $(\mathrm{A} \times \mathrm{B})$, and incubation time and shaking speed $(\mathrm{B} \times \mathrm{C})$. The studied parameters and their levels are shown in Table 1. An OA experimental design of $\mathrm{L}_{27}\left(3^{13}\right)$ was employed. The experimental design and data analysis (Table 2) was performed using Minitab software (Version 16, Minitab inc., PA, USA). All fermentations were carried out in triplicate in a fermentation volume of $50 \mathrm{~mL}$. 
Table 2. Experimental results of the methionol yields and calculated signal to noise $(\mathrm{S} / \mathrm{N})$ ratios (Taguchi OA of L-27)

\begin{tabular}{|c|c|c|c|c|c|c|c|c|}
\hline Run & $\begin{array}{l}\text { A: } \\
\text { Met }\end{array}$ & $\begin{array}{l}\text { B: } \\
\text { Incubation } \\
\text { time }\end{array}$ & $\begin{array}{l}\text { C: } \\
\text { Shaking } \\
\text { speed }\end{array}$ & $\begin{array}{l}\text { D: } \\
\text { YE }\end{array}$ & $\begin{array}{l}\text { E: } \\
\text { DAP }\end{array}$ & $\begin{array}{l}\text { F: } \\
\text { pH }\end{array}$ & $\begin{array}{l}\text { Average yield } \\
(\mu \mathrm{g} / \mathrm{mL})\end{array}$ & $\begin{array}{l}\mathrm{S} / \mathrm{N} \text { ratio } \\
\text { (decibel, } \mathrm{dB} \text { ) }\end{array}$ \\
\hline 1 & 1 & 1 & 1 & 1 & 1 & 1 & 34.1 & 29.3 \\
\hline 2 & 1 & 1 & 2 & 2 & 2 & 2 & 72.5 & 37.0 \\
\hline 3 & 1 & 1 & 3 & 3 & 3 & 3 & 447.7 & 52.8 \\
\hline 4 & 1 & 2 & 1 & 1 & 1 & 2 & 119.2 & 41.1 \\
\hline 5 & 1 & 2 & 2 & 2 & 2 & 3 & 113.7 & 40.5 \\
\hline 6 & 1 & 2 & 3 & 3 & 3 & 1 & 346.9 & 49.7 \\
\hline 7 & 1 & 3 & 1 & 1 & 1 & 3 & 188.0 & 45.0 \\
\hline 8 & 1 & 3 & 2 & 2 & 2 & 1 & 162.0 & 42.2 \\
\hline 9 & 1 & 3 & 3 & 3 & 3 & 2 & 414.1 & 52.2 \\
\hline 10 & 2 & 1 & 1 & 2 & 3 & 2 & 80.1 & 38.0 \\
\hline 11 & 2 & 1 & 2 & 3 & 1 & 3 & 105.4 & 40.1 \\
\hline 12 & 2 & 1 & 3 & 1 & 2 & 1 & 329.3 & 49.7 \\
\hline 13 & 2 & 2 & 1 & 2 & 3 & 3 & 167.1 & 43.6 \\
\hline 14 & 2 & 2 & 2 & 3 & 1 & 1 & 127.3 & 40.8 \\
\hline 15 & 2 & 2 & 3 & 1 & 2 & 2 & 670.0 & 56.1 \\
\hline 16 & 2 & 3 & 1 & 2 & 3 & 1 & 155.0 & 41.9 \\
\hline 17 & 2 & 3 & 2 & 3 & 1 & 2 & 269.4 & 45.5 \\
\hline 18 & 2 & 3 & 3 & 1 & 2 & 3 & 655.7 & 55.9 \\
\hline 19 & 3 & 1 & 1 & 3 & 2 & 3 & 110.4 & 40.8 \\
\hline 20 & 3 & 1 & 2 & 1 & 3 & 1 & 44.3 & 32.4 \\
\hline 21 & 3 & 1 & 3 & 2 & 1 & 2 & 678.4 & 56.0 \\
\hline 22 & 3 & 2 & 1 & 3 & 2 & 1 & 97.7 & 39.8 \\
\hline 23 & 3 & 2 & 2 & 1 & 3 & 2 & 170.4 & 44.4 \\
\hline 24 & 3 & 2 & 3 & 2 & 1 & 3 & 859.4 & 58.2 \\
\hline 25 & 3 & 3 & 1 & 3 & 2 & 2 & 190.4 & 44.5 \\
\hline 26 & 3 & 3 & 2 & 1 & 3 & 3 & 287.8 & 49.1 \\
\hline 27 & 3 & 3 & 3 & 2 & 1 & 1 & 559.6 & 54.7 \\
\hline
\end{tabular}

To investigate the effect of Met concentration on the bioproduction of methionol, $0.03 \mathrm{~g} / \mathrm{mL}$ of Met water solution was added to $40 \mathrm{~mL}$ of the coconut cream culture media in $2.5 \mathrm{~mL}, 5.0 \mathrm{~mL}$ and $7.5 \mathrm{~mL}$ portions to achieve the final concentrations of $0.15 \%, 0.30 \%$ and $0.45 \%(\mathrm{w} / \mathrm{v})$, respectively. The effect of YE level was studied by adding $0.5 \mathrm{~mL}$ of $0.05 \mathrm{~g} / \mathrm{mL}$ and $1.0 \mathrm{~mL}$ of $0.10 \mathrm{~g} / \mathrm{mL}$ of YE water solution to the coconut cream to attain the final concentrations of $0.05 \%$ and $0.20 \%(\mathrm{w} / \mathrm{v})$, respectively. In addition, the effect of nitrogen supplementation on methionol production was examined by adding $0.5 \mathrm{~mL}$ and $1.0 \mathrm{~mL}$ of DAP water solution at a concentration of $25.0 \mathrm{mg} / \mathrm{mL}$ in order to achieve the final concentrations of $250 \mathrm{mg} / \mathrm{L}$ and $500 \mathrm{mg} / \mathrm{L}$, respectively. This would in turn produce $53.0 \mathrm{mg} / \mathrm{L}$ and $106.1 \mathrm{mg} / \mathrm{L}$ of yeast assimilable nitrogen (YAN). In experimental trials where YE or DAP was at its lowest level, it was replaced by adding sterile deionized water instead (i.e. no supplementation). The final fermentation medium volumes were fitted to $50 \mathrm{~mL}$ with sterilized deionized water. Aeration effect was also studied by subjecting cultures to 3 different shaking speeds $(0,80$ and $160 \mathrm{rpm}$ ) in the shaking water bath (SW22, Julabo Labortechnik GmbH, Seelbach, Germany). To terminate the 
fermentation process, $1.0 \mathrm{M} \mathrm{HCl}$ was added to decrease the $\mathrm{pH}$ value to 2.5 . The samples were then immediately stored at $-20{ }^{\circ} \mathrm{C}$ until analysed.

\subsection{Sample Analysis}

Headspace solid-phase microextraction (HS-SPME) was used to extract the volatile flavour compounds from fermented samples. Five millilitres of sample diluted with deionized water (10-20 times) was put into a 20-mL SPME vial for HS extraction and analysis. The adsorption of volatile compounds was carried out with an $85 \mu \mathrm{m}$ carboxen-polydimethylsiloxane (CAR-PDMS) fibre (Supelco, Bellefonte, PA, USA). The SPME fibre was incubated with the samples at $80{ }^{\circ} \mathrm{C}$ for $30 \mathrm{~min}$ (shaking speed $250 \mathrm{rpm}$ ) to adsorb volatile compounds. After adsorption, the fibre was desorbed at the injector port and the released volatile compounds were analyzed using an Agilent (Palo Alto, CA, USA) 6890N network gas chromatography (GC) system equipped with a DB-FFAP capillary column $(60 \mathrm{~m} \times 0.25 \mathrm{~mm} \times 0.25 \mu \mathrm{m}), 5975$ inert mass selective detector (MSD) and flame ionization detector (FID). The carrier gas used was purified helium at a flow rate of $1.2 \mathrm{~mL} / \mathrm{min}$. The oven temperature was set at $50{ }^{\circ} \mathrm{C}$ for $5 \mathrm{~min}$, after which it was ramped to $230{ }^{\circ} \mathrm{C}$ at $5{ }^{\circ} \mathrm{C} / \mathrm{min}$ and kept for $10 \mathrm{~min}$. Splitless mode was applied, and the injector and detector temperatures were set at $250{ }^{\circ} \mathrm{C}$. The mass spectra information obtained from MSD was used for the identification of volatile compounds. The concentrations of methionol in all fermented samples were determined based on the peak area determined by FID. The calibration curve was established using external standard method by plotting FID peak areas against methionol ( $\geq 98 \%$, Sigma-Aldrich, St. Louis, MO, USA) standard concentrations.

\subsection{Taguchi Method and Analysis of Variance (ANOVA)}

The methionol concentrations in fermented coconut cream were determined and the corresponding $\mathrm{S} / \mathrm{N}$ ratios were calculated based on the larger-the-better $\mathrm{S} / \mathrm{N}$ ratio calculation formula as defined (Equation 1) (Adnani, Basri, Malek, Salleh, Abdul Rahman, Chaibakhsh, \& Rahman, 2010):

$$
\mathrm{S} / \mathrm{N} \text { ratio }=-10 \log \left(\frac{1}{r} \sum_{i=1}^{r} \frac{1}{y_{i}^{2}}\right)
$$

where $r$ represents the total number of tests in the orthogonal array, and $y_{i}$ is the observed data.

ANOVA was performed to determine the parameters that were statistically significant in affecting the bioproduction of methionol. In addition, the main effect and interaction plots were constructed to determine the optimum fermentation conditions. Under the determined optimum conditions, the predicted S/N ratios were calculated based on the Taguchi prediction formula (Peace, 1993). Confirmation runs were carried out in triplicate under the optimum fermentation conditions to validate the experimental design so that if the results of the confirmation runs were close to the predicted values, the optimum fermentation conditions can be implemented (Adnani et al., 2010). A large-volume fermentation of $500 \mathrm{~mL}$ was also carried out under the optimum fermentation conditions.

\section{Results and Discussion}

\subsection{Experimental Results}

Table 3. Mean $\mathrm{S} / \mathrm{N}$ ratios at different levels for each parameter

\begin{tabular}{llllll}
\hline \multirow{2}{*}{ Parameters } & \multicolumn{2}{l}{ Mean S/N ratio (dB) } & \multicolumn{2}{c}{ Rank } \\
\cline { 2 - 5 } & Level 1 & Level 2 & Level 3 & $\delta$ & \\
\hline A: Met & 43.3 & 45.7 & 46.7 & 3.4 & 4 \\
B: Incubation time & 41.8 & 46.0 & 47.9 & 6.1 & 2 \\
C: Shaking speed & 40.4 & 41.4 & 53.9 & 13.5 & 1 \\
D: YE & 44.8 & 45.8 & 45.1 & 1.0 & 5 \\
E: DAP & 45.6 & 45.2 & 44.9 & 0.7 & 6 \\
F: pH & 42.3 & 46.1 & 47.3 & 5.0 & 3 \\
\hline
\end{tabular}


The experimental data and the corresponding $\mathrm{S} / \mathrm{N}$ ratios were shown in Table 2. In an orthogonal experimental design, the effect of each parameter at the respective levels could be separated out (Zhou, Wu, \& Guo, 2010). For instance, the mean $\mathrm{S} / \mathrm{N}$ ratios for Met supplementation at levels 1, 2 and 3 were determined by calculating the average $\mathrm{S} / \mathrm{N}$ ratios for experimental runs 1 to 9,10 to 18 , and 19 to 27 , respectively. Similarly, the mean S/N ratios for the remaining parameters at their respective levels were also computed. As such, the $\mathrm{S} / \mathrm{N}$ ratio responses are shown in Table 3. The mean $\mathrm{S} / \mathrm{N}$ ratio range for each parameter was calculated by taking the difference in $\mathrm{S} / \mathrm{N}$ ratios between the levels that obtained the highest mean $\mathrm{S} / \mathrm{N}$ response and the lowest mean $\mathrm{S} / \mathrm{N}$ response. This range is represented by $\delta$ value. Determination of these $\delta$ values is important for ranking the parameters from the strongest to the weakest effect on the bioproduction of methionol where a high $\delta$ value would indicate that the parameter had a strong impact on the output signal response (Peace, 1993). From the experimental results, it was observed that shaking speed had the strongest effect on the bioproduction of methionol since its $\delta$ value was the highest. However, the effects of parameters like YE and DAP supplementation were weaker as their $\delta$ values were lower compared to the rest.

Table 4. ANOVA results based on the obtained experimental data ( $\mathrm{S} / \mathrm{N}$ ratios)

\begin{tabular}{llllll}
\hline Parameters & ${ }^{a} \mathbf{D F}$ & Sum of squares & Mean-square & F-value & $\begin{array}{c}{ }^{\mathbf{b}} \text { Prob }>\mathbf{F} \\
\boldsymbol{p} \text {-value }\end{array}$ \\
\hline A: Met & 2 & 54.28 & 27.14 & 6.44 & 0.032 \\
B: Incubation time & 2 & 176.76 & 88.38 & 20.96 & 0.002 \\
C: Shaking speed & 2 & 1021.18 & 510.59 & 121.08 & $<0.001$ \\
D: $\mathbf{Y E}$ & 2 & 4.72 & 2.36 & 0.56 & 0.599 \\
E: $\mathbf{D A P}$ & 2 & 2.38 & 1.18 & 0.28 & 0.764 \\
F: $\mathbf{p H}$ & 2 & 124.71 & 62.36 & 14.79 & 0.005 \\
$\mathbf{A} \times \mathbf{B}$ & 4 & 2.78 & 0.70 & 0.17 & 0.949 \\
$\mathbf{B} \times \mathbf{C}$ & 4 & 50.62 & 12.65 & 3.00 & 0.111 \\
Residual Error & 6 & 25.30 & 4.22 & & \\
Total & 26 & 1462.73 & & & \\
\hline
\end{tabular}

${ }^{a}$ Degree of Freedom.

${ }^{b}$ ANOVA was conducted at confidence level of $95 \%$ with $\alpha$ value of 0.05 .

In addition, statistically significant factors were determined through ANOVA. As listed in Table 4, the model terms that were statistically significant in this study were Met concentration, $\mathrm{pH}$, incubation time and shaking speed, which were ranked with increasing significance. Interestingly, the ranking sequence of significant parameters obtained from ANOVA was consistent with the ranking of influential parameters in Table 3. It was also observed that the studied interactions were not statistically significant, implying that the interactions between the assigned parameters were not distinct enough to affect the bioproduction of methionol.

\subsection{Main Effects and Interaction Plots}

The main effect plots corresponding to the different parameters are presented in Figure 2. The plots display the corresponding mean $\mathrm{S} / \mathrm{N}$ ratios of the respective levels of the parameters. Since Met is the precursor of methionol in Ehrlich pathway, a higher Met concentration would lead to the production of higher amounts of methionol. Indeed, as shown in Figure 2, such a trend was observed and was in agreement with several other studies (Liu \& Crow, 2010; Moreira, Mendes, Pereira, Guedes de Pinho, Hogg, \& Vasconcelos, 2002; Quek, Seow, Ong, \& Liu, 2011; Seow et al., 2010).

Incubation time is closely related to the growth and metabolism of the yeast. From Figure 2, it can be seen that longer incubation times resulted in higher methionol production. In an investigation conducted by Jiang on the fermentation by $K$. lactis, the changes of volatiles in the fermentation medium were reported with increasing incubation time (Jiang, 1995). These volatiles produced during fermentation are normally secondary metabolites which are usually biosynthesized when the growth of the yeast is limited due to nutrient exhaustion (Robinson, Singh, \& Nigam, 2001). However, Jiang's study reported that the production of volatile secondary metabolites 
by K. lactis was associated with its growing biomass (Jiang, 1995). Therefore, this suggests that the production of volatile secondary metabolites such as methionol may start during the initial growth phase of $K$. lactis but not necessarily start if and when the growth of K. lactis is limited. Similarly as observed in this study, the increasing incubation time resulted in the bioproduction of higher amounts of methionol. In this study, a correlation between methionol production and biomass could not be deduced as the cell count measurement of the experimental culture was not determined throughout the fermentation process. Therefore, a further study is required to investigate the relationship between methionol biosynthesis and yeast biomass.

A sharp increase in $\mathrm{S} / \mathrm{N}$ ratio was observed as the shaking speed increased from 80 to $160 \mathrm{rpm}$, with a maximum methionol concentration obtained at $160 \mathrm{rpm}$ (Figure 2). This is likely due to the aerobic nature of the K. lactis yeast (a respirofermentative yeast), where substantial shaking would provide sufficient oxygen for their growth and metabolism. This phenomenon was consistent with that observed in another study where the amount of methionol produced in the aerated ferment was nearly 5 times more than that in non-aerated ferment (Seow et al., 2010).

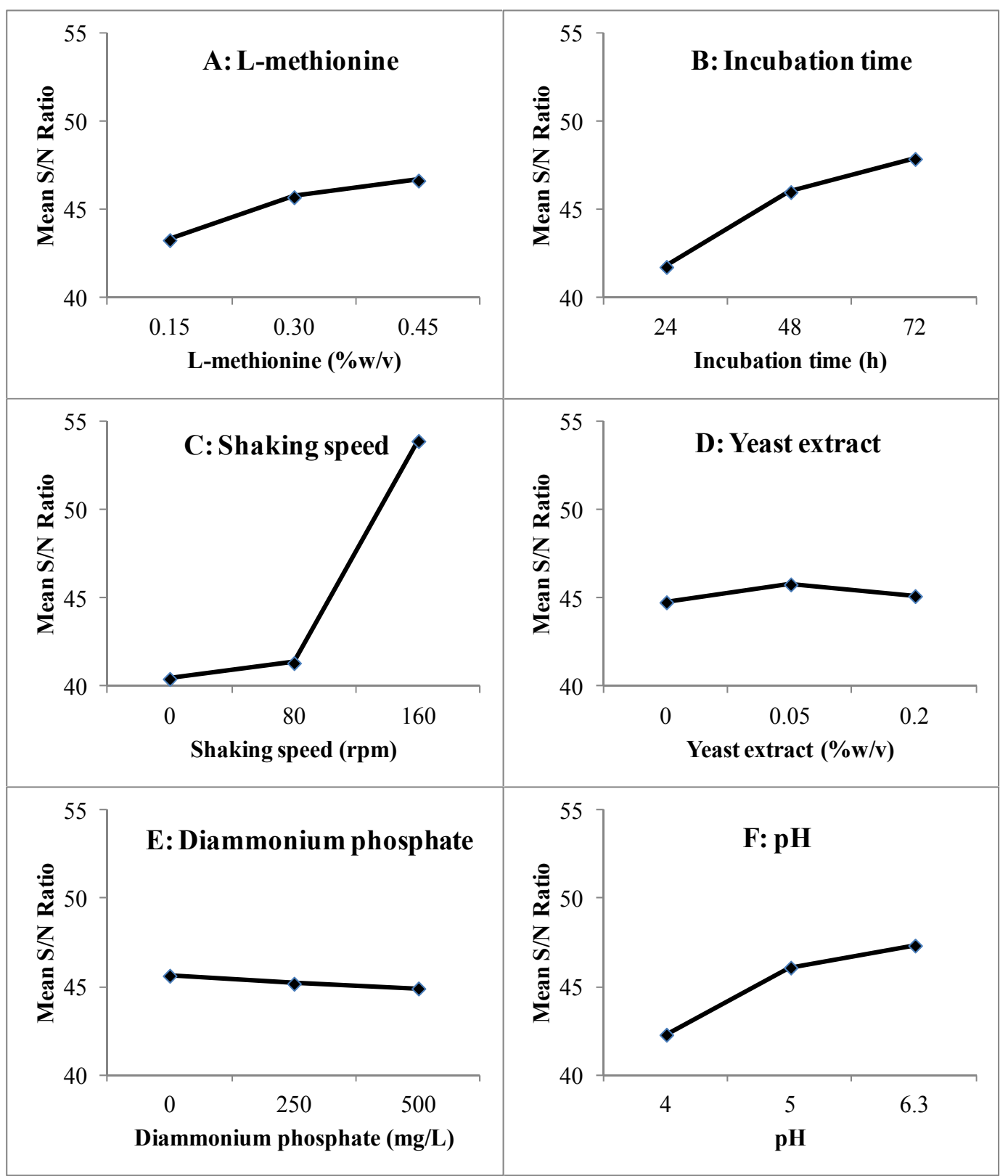

Figure 2. Main effects of parameters on the production of methionol ( $\mathrm{S} / \mathrm{N}$ ratio). The different data points in a single figure represent the average of $\mathrm{S} / \mathrm{N}$ ratio at different levels of this studied parameter. The results were calculated based on the experimental data shown in Table 2 
YE and DAP were introduced as growth and nutrient factors for $K$. lactis. Supplementation of YE was observed to cause a slight increase in $\mathrm{S} / \mathrm{N}$ ratio at the low concentration of $0.05 \%(\mathrm{w} / \mathrm{v})($ Figure 2). This could be due to the presence of nutrients such as vitamins and amino acids in the YE that contributed to the growth of an increasing yeast population. However, as the amount of YE continued to increase to a concentration of $0.20 \%$ $(w / v)$, the bioproduction of methionol decreased. Similar observations were reported in studies pertaining to $K$. lactis and S. cerevisiae fermentation and were attributed to nitrogen catabolite repression (Quek et al., 2011).

DAP was added as an inorganic nitrogen source for the nitrogen metabolism of yeast. However, it was found that the addition of DAP caused adverse effects on the bioproduction of methionol (Figure 2). A study similarly reported the decrease in the bioproduction of methionol and other volatile sulphur compounds when $300 \mathrm{mg} / \mathrm{L}$ of DAP was added into synthetic media containing S. cerevisiae (Rauhut, 2009). Another study also reported the inhibitory effect of ammonium chloride on VSFCs production by Williopsis yeast (Tan, Lee, Seow, Ong, \& Liu, 2012). In this current study, the decreased production of methionol at higher levels of YE and DAP could be attributed to $K$. lactis assimilating other amino acids and nitrogenous substances present in the YE and the inorganic nitrogen from DAP instead of Met (Rauhut, 2009; Seow et al., 2010). This could thus result in decreased production of methionol since less Met was catabolized by the yeast. However, the effects of YE and DAP supplementation on methionol biosynthesis were not statistically significant. This may due to the narrow concentration range of supplementation being employed in this research, which was not sufficient to create a significant impact on the bioproduction of methionol.

The fermentation medium $\mathrm{pH}$ level is one of the key factors that affect the growth of yeast and bioproduction of methionol. From Figure 2, it can be seen that a higher $\mathrm{pH}$ value of 6.3 was observed to favour the bioproduction of methionol. This result was different from a previous study (Seow et al., 2010), where an optimum fermentation medium $\mathrm{pH}$ for the bioproduction of methionol was 5.0, implying that the enzymatic activity and growth of $K$. lactis was optimum under slight acidic conditions. Although both $\mathrm{pH} 5.0$ and $\mathrm{pH} 6.3$ are weak acidic fermentation conditions, one possible explanation for the difference could be the different experimental design methods used. In that previous study, the optimum fermentation conditions were obtained through single factor experimental design. In the present study, the Taguchi method, which allows different combinations of varying levels of parameters within every experimental run, was used. This could cause influential effects on the growth of $K$. lactis, hence giving rise to the difference in the optimum $\mathrm{pH}$ determined by these two studies.

Two interactive effects were studied: Met level and incubation time, and incubation time and shaking speed. Met is the precursor to the bioproduction of methionol, it was interesting to investigate whether incubation time and Met concentration have interactive effects on the formation of methionol. Similarly, it would also be important to observe the interactive effects between aeration and incubation time. The constructed interaction plots are shown in Figure 3. Interaction effects were observed to be non-significant, since there was no intersection between the lines, indicating that these parameters were independent of each other. In addition, the Taguchi method emphasizes that when an interactive effect is not statistically significant, the analysis of the optimum conditions would be solely on the main effects plots (Peace, 1993). Thus, the preferred levels for the fermentation conditions in this study were selected based on the main effects. 


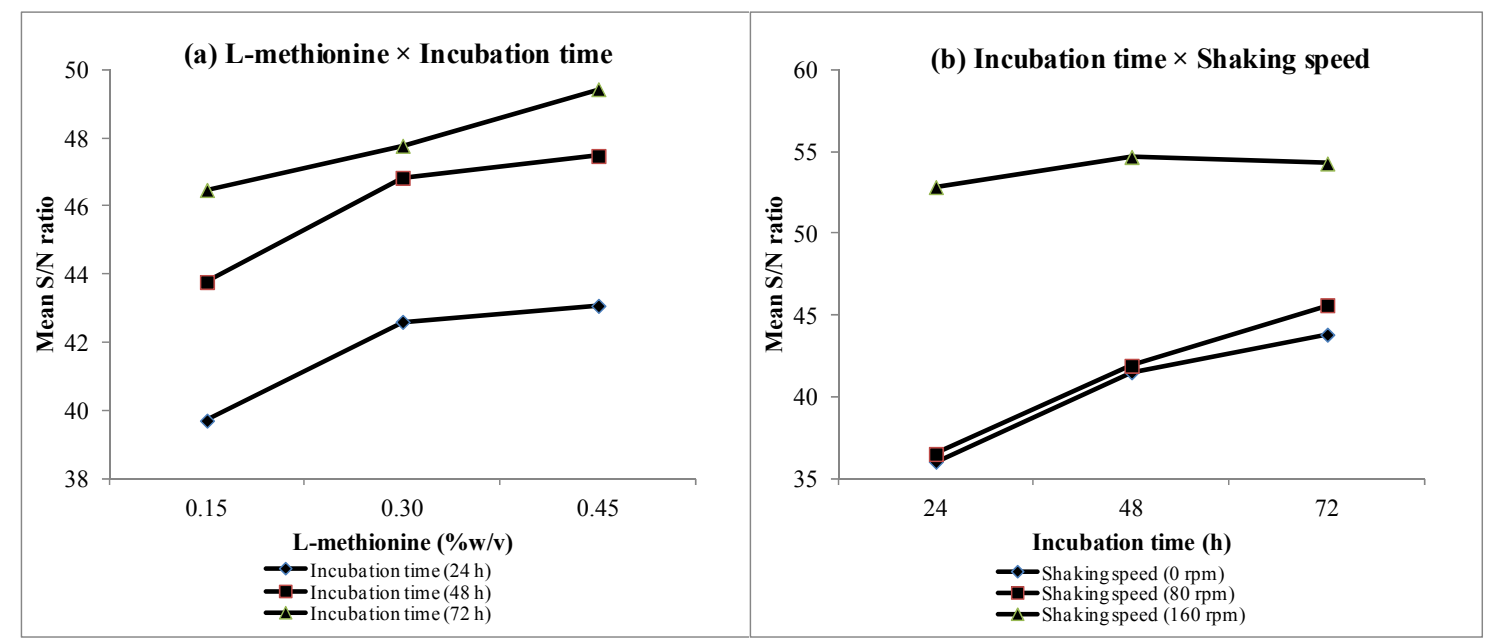

Figure 3. Interaction plots between parameters. (a) Met concentration and incubation time $(\mathrm{A} \times \mathrm{B})$; (b) Incubation time and shaking speed $(B \times C)$. The interaction between studied two parameters was shown by three lines, and each line was drawn by fixing one of these two parameters at the same level

\subsection{Confirmation Run and Scale-up Fermentation}

Since the interest was based on a larger-the-better characteristic, the focus was to determine the levels of each significant parameter that resulted in the highest $\mathrm{S} / \mathrm{N}$ ratio response. Cost-effective levels of the non-significant parameters such as YE could be implemented. Since $0.05 \%(\mathrm{w} / \mathrm{v})$ of YE supplementation was economically acceptable, this level of incorporation was adopted into the confirmation run. According to the main effects plots shown in Figure 2, the optimum level of each parameter that gave the highest $\mathrm{S} / \mathrm{N}$ ratio was chosen such as $0.45 \%(\mathrm{w} / \mathrm{v})$ of Met, $72 \mathrm{~h}$ of incubation time, $160 \mathrm{rpm}$ of shaking speed and $\mathrm{pH}$ 6.3. Less influential parameters such as YE and DAP, as well as weak interactions were not incorporated into the prediction equation to avoid an overestimate of the predicted $\mathrm{S} / \mathrm{N}$ ratio. Although $72 \mathrm{~h}$ of fermentation gave the highest average $\mathrm{S} / \mathrm{N}$ ratio, considering the economical aspects and the production efficiency, $48 \mathrm{~h}$ was selected as the optimum fermentation time since the difference between these predicted corresponding $\mathrm{S} / \mathrm{N}$ ratios was not significant. For $\mathrm{YE}$ and DAP, the level produced highest $\mathrm{S} / \mathrm{N}$ ratios according to main effect plots were selected as the optimum level which were $0.05 \%$ and $0 \mathrm{mg} / \mathrm{L}$ respectively. Therefore, the optimized fermentation conditions were determined as $A_{3}(0.45 \%), B_{2}(48 \mathrm{~h}), C_{3}(160 \mathrm{rpm}), \mathrm{D}_{2}(0.05 \%), \mathrm{E}_{1}(0 \mathrm{mg} / \mathrm{L})$ and $\mathrm{F}_{3}(\mathrm{pH} 6.3)$. Under the optimum conditions, the experimental $\mathrm{S} / \mathrm{N}$ ratio obtained was $59.9 \mathrm{~dB}$ which was close to the predicted $\mathrm{S} / \mathrm{N}$ ratio of 58.2 $\mathrm{dB}$. And an average methionol concentration of $990.1 \pm 49.7 \mu \mathrm{g} / \mathrm{mL}$ was achieved. A large-volume fermentation of $500 \mathrm{~mL}$ yielded an average methionol concentration of $766.0 \pm 24.5 \mu \mathrm{g} / \mathrm{mL}$. Using the Student's t-test, the bioproduction of methionol between $50 \mathrm{~mL}$ and $500 \mathrm{~mL}$ fermentation was found to be statistically different. This could be due to the difference in the dimensions of the glass bottles, where a $50 \mathrm{~mL}$ ferment subjected to shaking in a smaller bottle with lesser volume could result in more consistency during mixing.

Nevertheless, the experimental $\mathrm{S} / \mathrm{N}$ ratios of the confirmation runs were found to be in good agreement with the predicted $\mathrm{S} / \mathrm{N}$ ratio, having a low percentage deviation of $2.9 \%$. When the actual $\mathrm{S} / \mathrm{N}$ ratio was close to the predicted S/N ratio, the preferred levels of the parameters could be employed (Adnani et al., 2010; Kim, Choi, Choa, \& Kim, 2007). In addition, while the study conducted by Seow et al. (2010) obtained a methionol yield of $130.0 \mu \mathrm{g} / \mathrm{mL}$ in $1-\mathrm{L}$ aerated coconut cream fermented by $K$. lactis , the scale-up fermentation confirmation run in this study produced a much higher methionol concentration of $766.0 \mu \mathrm{g} / \mathrm{mL}$. Similarly, the amount of methionol produced by $K$. lactis fermentation in our study was observed to be higher than that reported in another study (Lopez del Castillo-Lozano et al., 2007). Therefore, the results indicated that the Taguchi method was effective in optimizing the bioproduction of methionol by K. lactis. However, future study could be done in the area of applying the RSM approach to the optimization of methionol bioproduction. Therefore, an RSM approach should be proposed as a follow-up study and a comparison between optimized conditions by these two experimental design methods can then be made. The fermented coconut cream can be applied as flavour ingredients to food industry after sensory evaluation. On the other hand, methionol can be extracted from the coconut cream medium through solvent extraction or membrane separation methods, and the obtained methionol could be further applied in food industry as pure flavour compound. 


\section{Conclusion}

In summary, the bioproduction of methionol by $K$. lactis in coconut cream supplemented with Met was successfully optimized using the Taguchi method. The main parameters that were observed to have a significant impact on methionol bioproduction were shaking speed, incubation time, $\mathrm{pH}$ and Met concentration. The experimental $\mathrm{S} / \mathrm{N}$ ratio of the confirmation runs under the optimized conditions was $59.9 \mathrm{~dB}$, which was in good agreement with the predicted $\mathrm{S} / \mathrm{N}$ ratio of $58.2 \mathrm{~dB}$. The amount of methionol produced in this study was also observed to be significantly higher compared to other studies. Therefore, the results suggest that the Taguchi method is effective in the optimization of methionol bioproduction by K. lactis. The application of RSM to optimize the bioproduction of methionol would be an ideal follow-up study to compare the results obtained by RSM and Taguchi method.

\section{References}

Adnani, A., Basri, M., Malek, E. A., Salleh, A. B., Abdul Rahman, M. B., Chaibakhsh, N., \& Rahman, R. N. Z. R. A. (2010). Optimization of lipase-catalyzed synthesis of xylitol ester by Taguchi robust design method. Industrial Crops and Products, 31(2), 350-356. http://dx.doi.org/10.1016/j.indcrop.2009.12.001

Bezerra, M. A., Santelli, R. E., Oliveira, E. P., Villar, L. S., \& Escaleira, L. A. (2008). Response surface methodology (RSM) as a tool for optimization in analytical chemistry. Talanta, 76(5), 965-977. http://dx.doi.org/10.1016/j.talanta.2008.05.019

Etschmann, M. M. W., Kötter, P., Hauf, J., Bluemke, W., Entian, K. D., \& Schrader, J. (2008). Production of the aroma chemicals 3-(methylthio)-1-propanol and 3-(methylthio)-propylacetate with yeasts. Applied microbiology and biotechnology, 80(4), 579-587. http://dx.doi.org/10.1007/s00253-008-1573-4

Jiang, J. (1995). Changes in volatile composition of Kluyveromyces lactis broth during fermentation. Developments in Food Science, 37, 1073-1086. http://dx.doi.org/10.1016/S0167-4501(06)80220-7

Kim, K. D., Choi, D. W., Choa, Y. H., \& Kim, H. T. (2007). Optimization of parameters for the synthesis of zinc oxide nanoparticles by Taguchi robust design method. Colloids and Surfaces A, 311(1-3), 170-173. http://dx.doi.org/10.1016/j.colsurfa.2007.06.017

Landaud, S., Helinck, S., \& Bonnarme, P. (2008). Formation of volatile sulfur compounds and metabolism of methionine and other sulfur compounds in fermented food. Applied microbiology and biotechnology, 77(6), 1191-1205. http://dx.doi.org/10.1007/s00253-007-1288-y

Liu, S. Q., \& Crow, V. (2010). Production of dairy-based, natural sulphur flavor concentrate by yeast fermentation. Food Biotechnology, 24(1), 62-77. http://dx.doi.org/10.1080/08905430903562724

Lopez del Castillo-Lozano, M., Delile, A., Spinnler, H., Bonnarme, P., \& Landaud, S. (2007). Comparison of volatile sulphur compound production by cheese-ripening yeasts from methionine and methionine-cysteine $\begin{array}{lllll}\text { mixtures. Applied microbiology and biotechnology, 75(6), 1447-1454. } & \text {. }\end{array}$ http://dx.doi.org/10.1007/s00253-007-0971-3

Mestres, M., Busto, O., \& Guasch, J. (2000). Analysis of organic sulfur compounds in wine aroma. Journal of chromatography A, 881(1), 569-581. http://dx.doi.org/10.1016/S0021-9673(00)00220-X

Moreira, N., Mendes, F., Pereira, O., Guedes de Pinho, P., Hogg, T., \& Vasconcelos, I. (2002). Volatile sulphur compounds in wines related to yeast metabolism and nitrogen composition of grape musts. Analytica Chimica Acta, 458(1), 157-167. http://dx.doi.org/10.1016/S0003-2670(01)01618-X

Peace, G. S. (1993). Taguchi methods: a hands-on approach. New York: Addison Wesley.

Prakasham, R., Rao, C. S., Rao, R. S., \& Sarma, P. (2005). Alkaline protease production by an isolated Bacilluscirculans under solid-state fermentation using agroindustrial waste: process parameters optimization. Biotechnology progress, 21(5), 1380-1388. http://dx.doi.org/10.1021/bp050095e

Quek, J. M. B., Seow, Y. X., Ong, P. K. C., \& Liu, S. Q. (2011). Formation of volatile sulfur-containing compounds by Saccharomyces cerevisiae in soymilk supplemented with L-methionine. Food Biotechnology, 25(4), 292-304. http://dx.doi.org/10.1080/08905436.2011.617254

Rao, R. S., Kumar, C. G., Prakasham, R. S., \& Hobbs, P. J. (2008). The Taguchi methodology as a statistical tool for biotechnological applications: a critical appraisal. Biotechnology journal, 3(4), 510-523. http://dx.doi.org/10.1002/biot.200700201 
Rao, R. S., Prakasham, R., Prasad, K. K., Rajesham, S., Sarma, P., \& Rao, L. V. (2004). Xylitol production by Candida sp.: parameter optimization using Taguchi approach. Process Biochemistry, 39(8), 951-956. http://dx.doi.org/10.1016/S0032-9592(03)00207-3

Rauhut, D. (2009). Usage and formation of sulphur compounds. In H. König, G. Unden \& J. Fröhlich (Eds.), Biology of Microorganisms on Grapes, in Must and in Wine (pp. 181-207). Berlin: Springer-Verlag.

Robinson, T., Singh, D., \& Nigam, P. (2001). Solid-state fermentation: a promising microbial technology for secondary metabolite production. Applied microbiology and biotechnology, 55(3), 284-289. http://dx.doi.org/10.1007/s002530000565

Ross, P. J. (1996). Taguchi techniques for quality engineering: loss function, orthogonal experiments, parameter and tolerance design (2nd ed.). New York: McGraw-Hill Professional.

Seow, Y. X., Ong, P. K. C., \& Liu, S. Q. (2010). Production of flavour-active methionol from methionine metabolism by yeasts in coconut cream. International Journal of Food Microbiology, 143(3), 235-240. http://dx.doi.org/10.1016/j.ijfoodmicro.2010.08.003

Tan, A. W. J., Lee, P. R., Seow, Y. X., Ong, P. K. C., \& Liu, S. Q. (2012). Volatile sulphur compounds and pathways of L-methionine catabolism in Williopsis yeasts. Applied Microbiology and Biotechnology, 95(4), 1011-1020. http://dx.doi.org/10.1007/s00253-012-3963-x

Ugliano, M., \& Henschke, P. A. (2009). Yeast and wine flavour. In M. V. Moreno-Arribas \& M. C. Polo (Eds.), Wine Chemistry and Biochemistry, (pp. 313-390). New York: Springer. http://dx.doi.org/10.1007/978-0-387-74118-5_17

Vandamme, E. J., \& Soetaert, W. (2002). Bioflavours and fragrances via fermentation and biocatalysis. Journal of Chemical Technology and Biotechnology, 77(12), 1323-1332. http://dx.doi.org/10.1002/jctb.722

Yvon, M., \& Rijnen, L. (2001). Cheese flavour formation by amino acid catabolism. International Dairy Journal, 11(4), 185-201. http://dx.doi.org/10.1016/S0958-6946(01)00049-8

Zhou, J., Wu, D., \& Guo, D. (2010). Optimization of the production of thiocarbohydrazide using the Taguchi method. Journal of Chemical Technology and Biotechnology, 85(10), 1402-1406. http://dx.doi.org/10.1002/jctb.2446

\section{Copyrights}

Copyright for this article is retained by the author(s), with first publication rights granted to the journal.

This is an open-access article distributed under the terms and conditions of the Creative Commons Attribution license (http://creativecommons.org/licenses/by/3.0/). 